\title{
CONTRACTS AND MONEY
}

\author{
Boyan Jovanovic \\ Masako Ueda
}

Working Paper 5637

\section{NATIONAL BUREAU OF ECONOMIC RESEARCH 1050 Massachusetts Avenue \\ Cambridge, MA 02138 \\ June 1996}

We thank Roland Benabou, Larry Christiano, John Coleman, Frank Diebold, Jordi Gali, Mark Gertler, Jeremy Greenwood, Chris Hanes, Marcos Lisboa, Glenn Rudebusch, and Oved Yosha for comments, and the National Science Foundation and the C.V. Starr Center for Applied Economics at New York University for financial assistance. This paper is part of NBER's research program in Productivity. Any opinions expressed are those of the authors and not those of the National Bureau of Economic Research.

(C) 1996 by Boyan Jovanovic and Masako Ueda. All rights reserved. Short sections of text, not to exceed two paragraphs, may be quoted without explicit permission provided that full credit, including (C) notice, is given to the source. 
NBER Working Paper 5637

June 1996

\title{
CONTRACTS AND MONEY
}

\begin{abstract}
We analyze the contractual relation between workers and their employers when there is nominal risk. The key feature of the problem is that the consumption deflator is random and observed sometime after the effort is exerted. The worker's effort is not observable, and to induce the agent to work, second-best contracts do not insure the worker fully. They do eliminate all nominal risk for the parties (by fully indexing the terms of the contracts to the price level) but they would be re-negotiated. Foreseeing this, the parties to the contract will write one that is renegotiation-proof. Under such a contract, nominal shocks affect real consumption. Since the argument should apply in many situations, it will have macroeconomic implications, one of which is short-run non-neutrality of money. We have found that surprise money is likely to redistribute consumption and welfare towards workers, and away from shareholders.
\end{abstract}

Boyan Jovanovic

Department of Economics

New York University

269 Mercer Street

New York, NY 10003

and NBER
Masako Ueda

The Wharton School

University of Pennsylvania

Philadelphia, PA 19104 


\section{Introduction}

A contract written in nominal terms exposes the parties to price-level risk. Full indexation to the price level is a device for eliminating such risk. Our paper shows that when nominal data are gathered with delay, a fully indexed contract would be renegotiated by the parties to that contract. That is, fully indexed contracts are not time consistent, not renegotiation proof. But contracts that specify an uncontingent nominal payment are not renegotiation-proof either.

When contracts are not fully indexed, monetary policy will affect the real terms of those contracts, and hence it will affect real variables. In general; three types of explanation have been proposed for how money affects real variables: "Menu Costs" models assume it is costly to change prices -- Sheshinski and Weiss (1977). "Surprise Money" models assume money influences expectations and affects spot market trades which can not be undone after the money shock is revealed -- Lucas (1972), Azariadis (1978), Eden (1994). "Asymmetric Injections" models assume that a subset of agents gets monetary injections -- Grossman and Weiss (1983), Rotemberg (1984), Christiano and Eichenbaum (1992).

Because price expectations are built into contracts, ours is a "Surprise Money" paper. It applies to the markets of the many goods and services that are traded not in impersonal spot markets but as part of a contractual arrangement. We focus on the contract between the firm and the worker. No nominal rigidity is imposed on the contract; since effort is unobservable, to elicit effort the firm does not insure the worker fully. Instead, the contract says the worker should get more money when his nominal output is high, and when the price level is high. When nominal output is observed, the worker's real reward is still uncertain because the price level is observed with delay. At this point, effort has been sunk, and so the principal may as well fully insure the agent against price-level risk. So, the principal now guarantees the agent a consumption whose level depends on the nominal output alone. But the latter reflects the money supply, and so money has real effects.

Two implications emerge. First, the worker gets more when price surprises are positive, so that labor's share is positively related to price surprises, and that the nominal wage varies more than the real wage [the latter is documented for the U.S., U.K., and Japan in Table 1 of Gordon (1982)]. It also means that the firm's price markup over cost should be negatively related to price surprises. Benabou (1992), Blanchard and Muet (1993), and Kaskarelis (1993) document this. A related implication is that positive money shocks raise the real wage, which is 
consistent with evidence in Table 5 of Christiano and Eichenbaum (1992).

The second implication is that surprise money lowers stock-returns. This explains the finding that unexpected inflation is negatively related with real stock prices -- Fama (1981, p. 545), Chen, Roll, and Ross (1986, tables 2 and 4), Chan, Chen, and Hsieh (1985, table 2), and Blanchard (1993, table 7). So, money has distributional effects even though we assume money is distributed in proportion to existing holdings.

Two final points: The model does not explain nominal rigidity; renegotiation-proof contracts are not fully indexed, but nominal transfers do depend on money shocks. Also, a random money-supply rule strictly lowers welfare -- a stronger result than in Lucas (1972) who showed only that predictable money-supply rules lead to a Pareto optimal equilibrium.

Section 2 gives the intuition for our results, while section 3 describes the equilibrium model. Section 4 presents the main welfare theorem, while section 5 gives the positive implications. Section 6 discusses the key assumptions, section 7 discusses some issues and problems, and section 8 concludes the paper.

\section{The Intuition}

Here are three related principal-agent problems that contain the intuition for our results. Problem 1 is the standard principal-agent problem. Problems 2 and 3 present the parties with price-level risk in a partial equilibrium context.

2.A. PROBLEM 1: A risk-neutral principal hires a risk-averse agent. The principal can not see the agent's effort, only output, $y$. The agent's effort influences $y$ as follows:

$$
\mathrm{F}_{\mathrm{n}}(\mathrm{y}) \equiv \text { Probability }\{\text { output } \leq \mathrm{y} \mid \text { effort }=\mathrm{n}\}
$$

Just two effort-levels, $\mathrm{n} \in\{0,1\}$ are possible. The agent's preferences over consumption $\mathrm{c}$, and effort $\mathrm{n}$, are

$$
\mathrm{U}(\mathrm{c}, \mathrm{n})=\mathrm{U}(\mathrm{c})-\mathrm{en}
$$


The parameter $\mathrm{e}$ is the marginal disutility of effort. The principal's utility is $\mathrm{y}-\mathrm{c}$. Assume that the principal wants the agent to choose effort $n=1$. Because $n$ is not observable, contracts can not condition on $\mathrm{n}$. Instead, the second-best contract specifies that the principal should pay the agent an amount $\mathrm{c}=\mathrm{c}(\mathrm{y})$ if output should equal $\mathrm{y}$. Let $\mathrm{c}^{*}(\mathrm{y})$ denote the second-best contract. This contract will not insure the agent fully (otherwise the agent would not choose $n=1$ ). That is, $c^{*}(y)$ can not be constant.

2.B. PROBLEM 2: Just like Problem 1, but now y is not directly observed by either party. For instance the principal could be the shareholders of a company, and the agent may be the CEO responsible for launching a new product. The quality of the product, $y$, is not observed and almost impossible to even define independently of sales. Instead, both parties see 2 signals separately. The first signal is "nominal output", denoted by s, which is given by

$$
\mathrm{s}=\mathrm{xy} .
$$

Here $\mathrm{x}$ is the price level. It is observed, and it is the second signal. Since $y \equiv s / x$, the contract $\mathrm{c}^{*}(\mathrm{~s} / \mathrm{x})$ will yield the same utility to both parties as in Problem 1 . The nominal transfer is $\mathrm{xc}^{*}(\mathrm{~s} / \mathrm{x})$, and it is homogeneous of degree one. This is a fully indexed contract -- the two parties are fully insulated from nominal-induced variations in their consumption. That is to say, the relative state-contingent prices -- the payments the agent gets in various states $\mathrm{y}$-- do not depend on $\mathrm{x}$. So money is neutral in the traditional sense of the word -- it affects neither real allocations, nor relative prices. Price shocks can be neutralized because effort is predetermined regardless the shock, and parties consume after the shock is observed.

2.C. PROBLEM 3: Just like Problem 2, but now $\mathrm{x}$ is observed (by both parties) with some delay. The signal $\mathbf{s}$ is observed first, immediately after the effort is sunk. The agent also knows n (the effort level he has chosen), but so does the principal, because he can infer it in equilibrium. At this point, then, the two parties have the same beliefs over $x$. Suppose that the realized value of this signal does not fully reveal $x$, so that the conditional density of $x$, call it $g(x \mid s)$, is nondegenerate. Since $\mathrm{c}^{*}($.$) is not a constant function, this implies that \mathrm{c}^{*}(\mathrm{~s} / \mathrm{x})$ will be a random variable even if $s$ is given. Now we shall show that, given the option to renegotiate, both parties will prefer a contract different from $c^{*}(s / x)$. Denote the realized value of the random variable $s$ by $s_{0}$. Having seen this signal, the expected utilities of the principal and agent [if they stick to the contract $\left.c^{*}(\mathrm{~s} / \mathrm{x})\right]$ are 


$$
\int\left[s_{0} / x-c^{*}\left(s_{0} / x\right)\right] g\left(x \mid s_{0}\right) d x \text { and } \int U\left[c^{*}\left(s_{0} / x\right)\right] g\left(x \mid s_{0}\right) d x
$$

Now write $\mathrm{C}\left(\mathrm{s}_{0}\right)$ for the certainty-equivalent of the random variable $\mathrm{c}^{*}\left(\mathrm{~s}_{0} / \mathrm{x}\right)$. That is, let $\mathrm{C}\left(\mathrm{s}_{0}\right)$ solve the equation

$$
\mathrm{U}\left[\mathrm{C}\left(\mathrm{s}_{0}\right)\right]=\int \mathrm{U}\left[\mathrm{c}^{*}\left(\mathrm{~s}_{0} / \mathrm{x}\right)\right] \mathrm{g}\left(\mathrm{x} \mid \mathrm{s}_{0}\right) \mathrm{dx}
$$

Since U(.) is strictly concave,

$$
C\left(s_{0}\right)<\int c^{*}\left(s_{0} / x\right) g\left(x \mid s_{0}\right) d x
$$

The principal is therefore strictly better off if he can induce the agent to accept $\mathrm{C}\left(\mathrm{s}_{0}\right)$. But the agent would accept such an offer, since he is [by definition of $\mathrm{C}\left(\mathrm{s}_{0}\right)$ ] indifferent. The intuition is that at the renegotiation stage, the tension between insurance and incentives has disappeared: effort has been sunk, the incentive compatibility condition is no longer relevant, and the principal should insure the agent fully. But then since both payoffs in (2.1) depend only on $s_{0}$ (and not on $\mathrm{x}$ ), any renegotiation procedure that leads to a point on the contract curve will have as its outcome a level of consumption for the agent that depends only on $s_{0}$.

2.D. Renegotiation proof contracts: In designing contracts that will not later be renegotiated, the parties will choose a contract from the class $c=C(s)$. That is, contracts under which the worker's consumption depends only on s. Moreover, $\mathrm{C}(\mathrm{s})$ will have to depend on $\mathrm{s}$; if it did not, it would be full insurance contract, and would therefore not elicit any effort from the agent. But if $C(s)$ depends on $s$, then a nominal shock $x$ will have real effects because it will influence $s$.

2.E. The nominal shock affects the division of the pie: The effort level $n$ is chosen before $x$ is realized. Therefore output does not depend on $\mathrm{x}$. The division of output, on the other hand, will depend on $\mathrm{x}$, and what is more, this dependence will likely be systematic. In particular, assuming that $F_{1}$ is stochastically larger than $F_{0}$, the contract will provide the "right" incentives if the function $\mathrm{C}($.$) is increasing, at least for the most part. But then the agent's share$ in output will be increasing in $\mathrm{x}$, and the principal's share will be decreasing.

2.F. Nominal contracts are not renegotiation proof: A nominally-rigid contract specifies a nominal payment, say W. It therefore specifies a consumption level of W/x. As shown in 2.C., 
such contracts are not renegotiation proof.

2.G. Key assumptions: That the nominal shock $\mathrm{x}$ will have real effects hinges on the following key assumptions embodied in Problem 3, and each of them is necessary:

(a) The principal can not see the agent's effort. Otherwise the principal could contract based on effort directly, and insure the agent fully.

(b) The quality of the output is not fully observed. Otherwise, real consumption could depend directly on $\mathrm{y}$ as in Problem 1.

(c) $\mathrm{s}$ is observed immediately, $\mathrm{x}$ only with some delay. Otherwise, if both $\mathrm{s}$ and $\mathrm{x}$ were observed immediately, we would have the situation described in Problem 2, in which the principal can guarantee the agent a real wage directly on the basis of real output. On the other hand, if (a) failed and both $\mathrm{s}$ and $\mathrm{x}$ were observed with delay, then renegotiation would take place right after effort is sunk, and the result would be full insurance in which $\mathrm{x}$ would be neutral.

(d) The two parties can not avoid renegotiation. Otherwise, the second-best contract of Problem 2 would be attainable.

These assumptions probably hold in many settings. We shall return to them in section 6 .

\section{The Model}

The examples in the last section assumed different attitudes towards risk by principals and agents. With a stock market, such differences in attitudes arise endogenously, as we shall now show in a monetary economy.

Preferences: There are 2-period lived overlapping generations. Effort takes on just two values: 1 and 0 . If a person exerts effort $=1$, their lifetime utility is $U(c)-e$, where $c$ is the consumption of efficiency units, which occurs in old age, and where $e$ is the disutility of a unit of effort, exerted when young. If no effort is exerted, lifetime utility is simply $U(c)$. The young work and their output is sold on a spot market to old agents, who simply consume it.

Storage and production: The young are born with an endowment of $\mathrm{K}>1$ units of the consumption good that they do not wish to consume. The endowment perishes too quickly to be marketed to the old agents. A young person can do one of two things with $\mathrm{K}$. He can store it, in which case he gets $\beta \mathrm{K}$ units of the consumption good in the next period. Or he can, at the beginning of the period, use it to buy shares that entitle him to dividends at the end of the period, 
which he can use to finance consumption in old age. There is also a production technology. Firms can produce output with labor and capital. Let y denote the quality of the output. The realization of the firm's output $y$ is uncertain, and has a distribution conditional on labor input, $\mathrm{n}$, and capital input $\mathrm{k}$. If $\mathrm{k}<1$, the firm will produce no output at all, and for $\mathrm{k}>1$, the marginal product of capital is zero. So, the firm will want exactly 1 unit of capital. Also, the firm can hire at most one worker, who supplies effort $n \in\{0,1\}$. Let

$$
\left.\mathrm{F}_{\mathrm{n}}(\mathrm{y})=\text { Probability\{output } \leq \mathrm{y} \mid \text { effort }=\mathrm{n} \text {, and } \mathrm{k} \geq 1\right\}
$$

Assume that under low effort the production sector can not "get off the ground" :

$$
\int \mathrm{ydF}_{0}(\mathrm{y})<\boldsymbol{\beta}
$$

[which implies that $\left.U(\beta K)>\int U[y+\beta(K-1)] \mathrm{dF}_{0}(\mathrm{y})\right]$. This means that firms will have to elicit high effort from their workers if they are to provide them with more utility than the workers can get by simply investing their capital in storage. This means that there can be no equilibrium in which workers make low effort. Second, assume that under high effort, the average product of capital exceeds its return in storage (both measured in utility):

$$
\int \mathrm{U}[\mathrm{y}+\boldsymbol{\beta}(\mathrm{K}-1)] \mathrm{dF}_{1}(\mathrm{y})-\mathrm{e}>\mathrm{U}(\beta \mathrm{K}) .
$$

(A1) and (A2) imply that even if the individual incurred all the risk from production, he would want to exert effort. Normalize $\int \mathrm{ydF}_{1}(\mathrm{y}) \equiv \mathrm{Y}=1$.

The money-supply rule: The supply of money at the start of a period is denoted by $\mathrm{m}$. The money supply rule consists of an injection $(\mathrm{x}-1) \mathrm{m}$ of nominal balances, distributed in proportion to existing holdings, and so only the old get money injections, and that these injections are proportional to their wages when young. The post-transfer money supply is $\mathrm{mx}$. We set $\mathrm{m}=1$ throughout, and assume that $\mathrm{x}$ is i.i.d., with $\operatorname{CDF} \mathrm{G}(\mathrm{x})$, and with density $\mathrm{g}(\mathrm{x})$.

Unobservable quality: We assume that $\mathrm{y}$ is not directly observed by the principal and the agent, as in the new product example of section 2. This makes sense if y stands for the quality of a differentiated product, or a product whose characteristics are hard to enumerate and describe objectively -- say a personal computer, or the services of a company's CEO. The 
assumption that $\mathrm{y}$ is not observed makes sense especially if people disagree about quality, as is the case in the following model -- an infinite-number-of firms version of the model in Perloff and Salop (1985), but without their restriction that each consumer buys at most one unit of a good.

A differentiated product market: Let $c_{i}$ denote the total number of efficiency units of output consumed by buyer i. Consumers have McFadden-type random preferences over the infinite number of differentiated products supplied. The output of firm $j$ contributes to $c_{i}$ an amount $z_{i, j}$ per efficiency unit; $z_{i, j}$ is i.i.d over $i$ and $j$, with an upper bound of $z_{\max }$. This means that if the quality of firm j's product is $y_{j}$, consumer i's consumption of efficiency units is effectively equal to $y_{j} z_{i, j}$, and the consumer derives utility $U\left(y_{j} z_{i, j}\right)$. This consumer will buy from whichever firm offers him the largest number of efficiency units per dollar spent. Let $p_{j}$ be the price of the product of firm $j$. Then consumer $i$ will buy from firm $j$ if

$$
\frac{y_{j} z_{i, j}}{p_{j}} \geq \max _{k \neq j} \frac{y_{k} z_{i, k}}{p_{k}}
$$

We now show that there is a number $p$ such the price $p_{j}=p y_{j}$ is an equilibrium price. That is, the equilibrium price per efficiency unit will be $\mathrm{p}$. We start out by supposing that $\mathrm{p}_{\mathbf{k}} / \mathrm{y}_{\mathbf{k}}=\mathrm{p}$. Since there are an infinite number of firms, the above inequality states that with probability one (assuming that $\mathrm{z}$ has density in a neighborhood below $\mathrm{z}_{\max }$ )

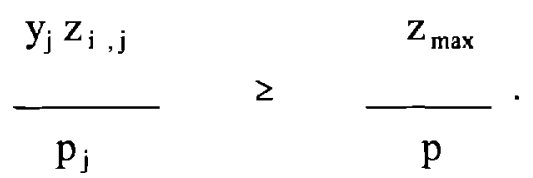

Since $z_{i, j} \leq z_{\max }$, this means that $y_{j} / p_{j} \geq 1 / p$, that is, $p_{j} \leq p y_{j}$. To sell any output, the firm's output must cost no more than $p$ per unit of efficiency. And at a price less than $p$, the firm's price per efficiency unit will be less than its competition, and there would be infinite excess demand. Aggregate nominal supply is $\mathrm{pY}=\mathrm{p}$ (since $\mathrm{Y}=1$ ). It must equal aggregate nominal demand, $x$, and so

$$
\mathrm{p}=\mathrm{x}
$$

Therefore, in its effect on the price level, money is neutral. Each seller sees only his own sales $\mathrm{s}$ $=\mathrm{xy}$, and cannot disentangle $\mathrm{x}$ from $\mathrm{y}$.

It is important to note that the seller sees his sales (i.e., his own price per unit of quantity) 
and only his own sales right away. Since he doesn't see the sales of other sellers this is not enough to reveal the price level $\mathrm{x}$ to him, because he does not know the quality of his product relative to that of other sellers.

Given income $w$ and given $x$, the buyer consumes $z_{\max } w / x$ with certainty. So $z_{\max }$ behaves as a parameter of the utility function, and we shall set it equal to 1 .

The labor market: The "price" of a young worker is an incentive-compatible contract, $w(s, x)$, which specifies the nominal amount the worker is to get as a function of the sales that he generates, $s$, and as a function of the money-supply shock, $x$.

Firms: There are one-period-lived firms, that are liquidated at the end of the period. They have access to the production technology described above. These firms are traded at the beginning of the period. The firm requires exactly 1 unit of capital (that dies with the firm at the end of the period), and they can employ exactly one worker. Under full employment, the number of firms will equal the number of young agents, which also equals the number of investors, and the measure of each is unity. Suppose that a firm signs a wage contract with its worker that specifies how much the worker will get if sales equal $\mathrm{s}$, and if the price-level shock is $\mathrm{x}$. Suppose that the contract is described by the function $w(s, x)$. The firm's dividend then is

$$
\delta(\mathrm{s}, \mathrm{x}) \equiv \mathrm{s}-\mathrm{w}(\mathrm{s}, \mathrm{x})
$$

Since they need exactly one unit of capital to operate, the supply of firms is infinitely elastic at the price of unity. So the equilibrium price of each firm is 1 , and since the measure of all firms is 1 , the total equity investment by the young will, in equilibrium, equal 1. Of course, dividends will need to be such as to make investors want to hold the right fraction of safe and risky assets in their portfolios.

The portfolio decision: Young investors are born with an endowment of $\mathrm{K}$. This endowment is perishable -- it perishes too soon to be sold to old agents, and is therefore of no value to the young agent unless it is invested right away. If stored, it yields a unit return of $\beta$. [Although one can think of storage as the return obtained from a fully-indexed safe asset, like an indexed Treasury Bill, formally, we treat storage as a process that each consumer undertakes himself, and the proceeds of which he consumes directly].

Total investment, $\mathrm{K}$, will consist of $\mathrm{R}$ units in the risky asset (the risky market 
portfolio) and the remaining $\mathrm{K}-\mathrm{R}$ units in the safe asset. If $\sigma_{\mathrm{j}}$ denotes the share of firm $\mathrm{j}$ 's shares in the investor's risky assets, investor i's nominal assets at the end of the period will then be

$$
R \int \sigma_{j} \delta\left(s_{j}, x\right) d j+x \beta(K-R)+w\left(s_{i}, x\right)
$$

where $w\left(s_{i}, x\right)$ is the wage paid by the firm that investor $i$ works for.

If $f_{n}(y)$ is the density of the distribution $F_{n}(y)$, the density of $s$ conditioned on $x$ is $\mathrm{x}^{-1} \mathrm{f}_{\mathrm{n}}(\mathrm{s} / \mathrm{x})$. The realizations of $\mathrm{y}$ are assumed to be independent across firms, and the dividend on the risky market portfolio in state $\mathrm{x}$ is

$$
\delta(x)=\int[s-w(s, x)] x^{-1} f_{1}(s / x) d s
$$

Let $\mathrm{c}(\mathrm{s}, \mathrm{x})$ be the worker's consumption if he ends up with sales $\mathrm{s}$ when the price level is $\mathrm{x}$, and his portfolio allocates equal weight to all firms. Then (anticipating the equilibrium allocation of $\mathrm{R}=1$ ),

$$
c(s, x)=\frac{\delta(x)+x \beta(K-1)+w(s, x)}{x},
$$

Also, let $h_{n}(s, x) \equiv(1 / x) f_{n}(s / x) g(x)$ be the joint density of $s$ and $x$ conditional on effort.

The value of a firm: Firms are traded at the outset, among the young. The demand-price of a share in firm $j$ is defined to be $V_{j}$ in units of the consumption good.

PROPOSITION 1: The market value of firm $\mathrm{j}$ is

$$
V_{j}=\beta^{-1} \int \theta(x)\left\{\int\left[\delta\left(s_{j}, x\right) / x\right] x^{-1} f_{1}\left(s_{j} / x\right) d s_{j}\right\} d x=\beta^{-1} E\left\{\theta(x) \delta\left(s_{j}, x\right) / x\right\}
$$

where

$$
\theta(x)=\frac{\int U^{\prime}[c(s, x)] h_{1}(s, x) d s}{\int U^{\prime}\left[c\left(s, x^{\prime}\right)\right] h_{1}\left(s / x^{\prime}\right) g\left(x^{\prime}\right) d s d x^{\prime}} \equiv \frac{E\left\{U^{\prime}(.) \mid x\right\}}{\int E\left\{U^{\prime}(.) \mid x^{\prime}\right\} g\left(x^{\prime}\right) d x^{\prime}}
$$


is the (normalized) expected marginal utility of income in state $\mathrm{x}$.

PROOF: In the appendix.

If all firms follow the same $w(s, x)$ policy, the value of the market portfolio is

$$
V=\beta^{-1} \int \theta(x)[\delta(x) / x] g(x) d x=\beta^{-1} E\{\theta(x) \delta(x) / x\}
$$

Equilibrium in the market for shares: The expression for $V_{j}$ is the demand-price for a firm's shares as a function of the properties of the firm's dividend. We assume that firms can not store capital and return it in the form of dividends or in the form of wages at the end of the period. Firms need capital only for productive purposes. Therefore, firms demand exactly one unit of capital -- per firm and in the aggregate. Firms will not want to pay any more dividends than it takes to extract this unit of capital from the investors, and certainly they can't get enough capital if they pay less. In equilibrium, then, $V_{j}=V=1$. This means that to attract capital, firm $\mathrm{j}$ must pay dividends such that $E\left\{\theta(\mathrm{x}) \delta\left(\mathrm{s}_{\mathrm{j}}, \mathrm{x}\right) / \mathrm{x}\right\} \geq \beta$. This inequality is imposed as a constraint on problem (3.7) below; however, since the firm will not want to pay any more than it has to, this constraint will hold with equality.

Note three things about the stock market equilibrium. First, if $x$ is not random $(x \equiv 1)$, there is no aggregate risk, and no risk-premium. Since $\theta(1)=1$ and $V=1$, (3.4) implies that $\delta(1)=\beta$, a no arbitrage requirement.

Second, when $\mathrm{x}$ is random, each firm uses $\theta(\mathrm{x})$ to value its real profits in state $\mathrm{x}$, because this is how its shareholders will value their dividend incomes in that state. Its dividends are distributed to the cross-section of workers. The formula for $V_{j}$ is the familiar one: Firm $j$ is worth more if $\delta\left(\mathrm{s}_{\mathrm{j}}, \mathrm{x}\right)$ is positively correlated with the marginal utility of consumption. Also, in general, there is a risk-premium associated with the diversified portfolio, in that $\beta^{-1} \mathrm{E}\{\delta(\mathrm{x}) / \mathrm{x}\}$ $\neq 1$. As the proof of Proposition 1 shows, the "excess return", $\delta(x) / x-\beta$, satisfies the equation

$$
\int \theta(x)(\delta(x) / x-\beta) g(x) d x=0
$$

And third, the stock of a worker's own firm is significantly correlated with his income. 
So why not hold (or sell short) a significant fraction of his portfolio in his own firm? We shall see that this is exactly what the optimal wage contract does for the worker -- it gives him the optimal weight in his portfolio of his own firm. The worker's holdings of his own firm's shares depend of his incentives.

Renegotiation-Proof Contracts: After they see s, the two parties hold the beliefs:

$$
g(x \mid s)=\frac{h_{1}(s, x)}{\int h_{1}\left(s, x^{\prime}\right) d x^{\prime}} .
$$

Given a contract $w$, a worker who has sales $s$, but who does not yet know the price level can guarantee himself an expected utility of

$$
\mathrm{U}^{*}(\mathrm{~s} ; \mathrm{w}) \equiv \int \mathrm{U}[\delta(\mathrm{x}) / \mathrm{x}+\beta(\mathrm{K}-1)+\mathrm{w}(\mathrm{s}, \mathrm{x}) / \mathrm{x}] \mathrm{g}(\mathrm{x} \mid \mathrm{s}) \mathrm{dx}
$$

The firm can guarantee its shareholders the expected payoff

$$
\mathrm{V}^{*}(\mathrm{~s} ; \mathrm{w}) \equiv \int \theta(\mathrm{x})[\mathrm{s} / \mathrm{x}-\mathrm{w}(\mathrm{s}, \mathrm{x}) / \mathrm{x}] \mathrm{g}(\mathrm{x} \mid \mathrm{s}) \mathrm{dx}
$$

For any $\pi \in[0,1]$, any $s$, and any contract $w_{0}$, let

$$
\Omega\left(\mathrm{s}, \mathrm{w}_{0}, \pi\right) \equiv \operatorname{argmax}_{\mathrm{w}}\left\{\pi \mathrm{V}^{*}(\mathrm{~s} ; \mathrm{w})+(1-\pi) \mathrm{U}^{*}(\mathrm{~s} ; \mathrm{w})\right\}
$$

subject to $\mathrm{V}^{*}(\mathrm{~s}, \mathrm{w}) \geq \mathrm{V}^{*}\left(\mathrm{~s}, \mathrm{w}_{0}\right), \mathrm{U}^{*}(\mathrm{~s}, \mathrm{w}) \geq \mathrm{U}^{*}\left(\mathrm{~s}, \mathrm{w}_{0}\right)$, and $0 \leq \mathrm{w}(\mathrm{s}, \mathrm{x}) \leq \mathrm{s}$ for all $\mathrm{x}$. These two constraints express the fact that both parties must agree to a renegotiation. As $\pi$ varies between zero to one, we trace out the contract curve (in the Edgeworth box sense) between the utilities defined by $V^{*}\left(s, w_{0}\right)$ and $U^{*}\left(s, w_{0}\right)$ (this is true because since the problem is convex in $\mathrm{w}$, the utility-possibility curve is concave to the origin). In particular, $\pi=0$ transfers any "interim" rents to the worker, and $\pi=1$ transfers them to the firm.

The following definition says that a renegotiation-proof contract must be Pareto Optimal 
for each $s$, given the parties interim preferences: ${ }^{2}$

DEFINITION 1: A Renegotiation Proof Contract satisfies $w \in \cup_{\mathrm{s}, \pi} \Omega(\mathrm{s}, \mathrm{w}, \pi)$.

Consider the maximization problem that defines $\Omega($.). Form the Lagrangean, with the multipliers $v(s)$ and $\chi(s)$ attached to the two constraints:

$$
\begin{aligned}
\mathscr{L}(\mathrm{s})= & \pi \mathrm{V}^{*}(\mathrm{~s} ; \mathrm{w})+(1-\pi) \mathrm{U}^{*}(\mathrm{~s} ; \mathrm{w})+\mathrm{v}(\mathrm{s})\left[\mathrm{V}^{*}(\mathrm{~s}, \mathrm{w})-\mathrm{V}^{*}\left(\mathrm{~s}, \mathrm{w}_{0}\right)\right]+\chi(\mathrm{s})\left[\mathrm{U}^{*}(\mathrm{~s}, \mathrm{w})-\mathrm{U}^{*}\left(\mathrm{~s}, \mathrm{w}_{0}\right)\right] \\
& +\int \xi(\mathrm{s}, \mathrm{x})[\mathrm{s}-\mathrm{w}(\mathrm{s}, \mathrm{x})] \mathrm{g}(\mathrm{x} \mid \mathrm{s}) \mathrm{dx} .
\end{aligned}
$$

The multipliers $\mathrm{v}(\mathrm{s}), \chi(\mathrm{s})$, and $\xi(\mathrm{s}, \mathrm{x})$ are nonnegative because $\mathscr{L}(\mathrm{s})$ is decreasing in the constraint parameters $\mathrm{V}^{*}\left(\mathrm{~s}, \mathrm{w}_{0}\right), \mathrm{U}^{*}\left(\mathrm{~s}, \mathrm{w}_{0}\right)$, and $\mathrm{s}$. This leads to the first order condition that must hold for each $(\mathrm{s}, \mathrm{x})$. Differentiating with respect to $\mathrm{w}(\mathrm{s}, \mathrm{x})$,

$$
-\xi(s, x)-[\pi+v(s)] \theta(x) / x+[1-\pi+\chi(s)](1 / x) U^{\prime}(.)=0
$$

The second-order derivative with respect to $\mathrm{w}$ is everywhere negative because $\mathrm{U}$ (and therefore $\mathrm{U}^{*}$ ) is concave, while $\mathrm{V}^{*}$ is linear . From the above, we get the following expression:

$$
\mathrm{U}^{\prime}[\mathrm{c}(\mathrm{s}, \mathrm{x})]=\frac{\mathrm{x} \xi(\mathrm{s}, \mathrm{x})+[\pi+\mathrm{v}(\mathrm{s})] \theta(\mathrm{x})}{[1-\pi+\chi(\mathrm{s})]}
$$

LEMMA 1: A contract $w$ is renegotiation-proof if and only if it affords the worker a consumption-level

$$
c(s, x ; \gamma) \equiv \max \left\{\delta(x) / x+\beta(K-1), \min \left\{[s+\delta(x)] / x+\beta(K-1), U^{\prime}-1[\theta(x) \gamma(s)]\right\}\right\}
$$

where the function $\gamma($.$) is real-valued, and does not depend on \mathrm{x}$.

PROOF: "Only if": Solving (3.6) for $w($.$) , we observe that if \xi(s, x)=0, c(s, x ; \gamma)<[s+$

2 Our renegotiation-proof allocation is interim Pareto optimal and unique given any $\pi$, so there is no renegotiation process under which both parties would agree to change this allocation. Maskin and Tirole (1992) formalized this notion as strong renegotiation proofness. 
$\delta(\mathrm{x})] / \mathrm{x}+\beta(\mathrm{K}-1)$ and noting that $\pi, \mathrm{v}(\mathrm{s})$, and $\chi(\mathrm{s})$ do not depend on $\mathrm{x}$, shows that in this event $\mathrm{c}(\mathrm{s}, \mathrm{x} ; \gamma)=\mathrm{U}^{\prime-1}[\theta(\mathrm{x}) \gamma(\mathrm{s})]$. On the other hand, $\xi(\mathrm{s}, \mathrm{x})>0$ implies that the constraint binds, so that in this event, $c(s, x ; \gamma)=[s+\delta(x)] / x+\beta(K-1)$. Finally, if $\gamma(\mathrm{s})$ were such that $c(s, x$; $\gamma)<\delta(x) / x+\beta(\mathrm{K}-1)$, wages would be negative.

"If": First, such a contract satisfies the limited liability condition. Second, it can not be bettered on the region of $(s, x)$-space on which it satisfies limited liability strictly. More specifically, for all $\left(x, x^{\prime}, s\right)$ such that $\xi(s, x)=\xi\left(s, x^{\prime}\right)=0$, the contract equates the ratio of the two parties marginal utilities of real income:

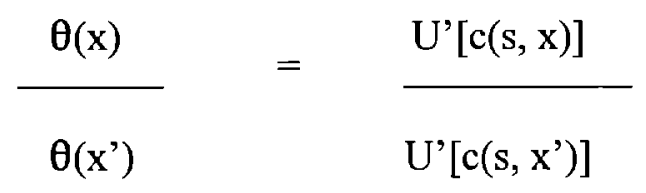

Among contracts in which the worker's real compensation depends only on aggregate risk, this contract is Pareto optimal -- it is on the contract curve. Third, it remains to be shown that the worker would reject any fair gamble that would transfer income from states in which $\xi(\mathrm{s}, \mathrm{x})=0$ to and from states in which $\xi(\mathrm{s}, \mathrm{x})>0$. But the worker would take such a gamble only if it transferred consumption from states in which $U^{\prime}(c)$ is low, to states in which it is high. But it follows from (3.6) that his consumption is lowest (and hence his U' highest) in the states where $\xi(\mathrm{s}, \mathrm{x})>0$, and the firm can not transfer consumption to this state without violating the limited liability condition.

Note first that if $\theta(x)$ were constant (which it will be when the utility function is quadratic), $\gamma(\mathrm{s})$ is just the worker's marginal utility of consumption. The second consequence of the lemma is stated more formally:

COROLLARY: Lotteries (i.e., random functions $w$ ) at the renegotiation stage are not renegotiation-proof.

PROOF: Suppose $\mathrm{w}_{0}$ were a lottery, a function of $\mathrm{s}, \mathrm{x}$, and a random variable. Extending the definitions of $\mathrm{V}^{*}$ and $\mathrm{U}^{*}$ in the obvious way, the only way $\mathrm{w}_{0}$ enters the maximization problem is though the scalars $\mathrm{V}^{*}\left(\mathrm{~s}, \mathrm{w}_{0}\right)$ and $\mathrm{U}^{*}\left(\mathrm{~s}, \mathrm{w}_{0}\right)$. Because the agent is risk averse, the constraint-set is still convex. Setting $\mathrm{w}_{0}$ to its mean (conditional on $(\mathrm{s}, \mathrm{x})$ ) makes the agent strictly better off without violating either rationality constraint. 
The optimal contract: We now formulate the firm's decision problem in light of the constraint that any contract it chooses must be renegotiation-proof. The firm uses contracts w(s, $\mathrm{x})$ to bid for workers under the added constraints that its shareholders get the market rate of return $\mathrm{V}$, and the limited liability constraint. Omitting the $\mathrm{j}$ subscript, the firm, taking $\theta(\mathrm{x})$ and $\delta(x)$ as given, solves the problem of maximizing its worker's utility:

$$
\begin{aligned}
& \operatorname{Max} \int U[c(s, x)] h_{1}(s, x) d s d x-e, \\
& w(.)
\end{aligned}
$$

subject to the constraint that its shareholders get at least the market rate of return,

$$
\int \theta(x) \int[s / x-w(s, x) / x] h_{1}(s, x) d s d x \geq \beta,
$$

subject to the incentive compatibility constraint that ensures effort is elicited,

$$
\iint U[c(s, x)]\left\{h_{1}(s, x)-h_{0}(s, x)\right\} d s d x-e \geq 0,
$$

subject to the limited liability constraint,

$$
\mathrm{s}-\mathrm{w}(\mathrm{s}, \mathrm{x}) \geq 0,
$$

subject to a non-negativc wage constraint, $w \geq 0$, and subject to the constraint that the contract be renegotiation proof. Here $\mathrm{c}(\mathrm{s}, \mathrm{x})$ is given by (3.2). Now in view of Lemma 1 , we know that the non-negative wage constraint, the limited liability constraint, and the renegotiationproofness constraint will be met if we substitute $c(s, x ; \gamma)$ for $c(s, x)$ in the above problem and then let the firm choose $\gamma(\mathrm{s})$ instead of $w($.$) . After this is done, the Lagrangean is$

$$
\begin{aligned}
\mathscr{L}= & \int \mathrm{U}[\mathrm{c}(\mathrm{s}, \mathrm{x} ; \gamma)] \mathrm{h}_{1}(\mathrm{~s}, \mathrm{x}) \mathrm{dsdx} \\
+ & \int \theta(\mathrm{x})\left\{\int[\mathrm{s} / \mathrm{x}+\beta(\mathrm{K}-1)+\delta(\mathrm{x}) / \mathrm{x}-\mathrm{c}(\mathrm{s}, \mathrm{x} ; \gamma)] \mathrm{h}_{1}(\mathrm{~s}, \mathrm{x}) \mathrm{ds}\right\} \mathrm{dx} \\
+\mu & {\left[\int \mathrm{U}[\mathrm{c}(\mathrm{s}, \mathrm{x} ; \gamma)]\left\{\mathrm{h}_{1}(\mathrm{~s}, \mathrm{x})-\mathrm{h}_{0}(\mathrm{~s}, \mathrm{x})\right\} \mathrm{ds} \mathrm{dx}-\mathrm{e}\right] }
\end{aligned}
$$


DEFINITION 2: Equilibrium consists of five functions: $\gamma(\mathrm{s}), \delta(\mathrm{x}), \theta(\mathrm{x}), \mathrm{w}(\mathrm{s}, \mathrm{x})$ and $\mathrm{c}(\mathrm{s}, \mathrm{x})$ that satisfy equations (3.1) - (3.3), (3.6) and the restrictions in the maximization problem (3.7).

THEOREM 1 (EXISTENCE): Suppose that

(i) The supports of $F_{0}, F_{1}$, and $G$ are finite intervals, excluding zero.

(ii) $f_{1}$ and $f_{0}$ are Lipschitz functions.

(iii) $\mathrm{U}(\mathrm{c})=\mathrm{a}_{0}+\mathrm{ac}-(1 / 2 \mathrm{~b}) \mathrm{c}^{2}$, with $\mathrm{ab}>\mathrm{y}_{\max }+\beta(\mathrm{K}-1)$

Then an equilibrium exists.

PROOF: In the appendix.

\section{Welfare}

\section{THEOREM 2 (RANDOM MONEY-SUPPLY RULES STRICTLY REDUCE WELFARE):}

When monetary policy is random, welfare is strictly less than in the case where money supply is constant (or deterministic). ${ }^{3}$

PROOF: The standard principal agent problem without renegotiation is a concave programming problem, and the optimal (second-best) contract is deterministic. This is seen by taking the worker's utility level as the control. The second-best contract is also unique. Under the constant money supply rule, there is no delayed signal, $\mathrm{x}$, and hence the second-best contract is renegotiation proof. In this contract, U' must depend only on $y$, that is, only on the ratio $s / x$. If an equilibrium contract under a random monetary rule were to yield the same utility, U' would have to depend only on the ratio $s / x$, because only then would the agent's real compensation not a function of the random variable $\mathrm{x}$. Now this would hold in (3.6) if limited liability were to bind for all states, but then there would be no dividends, and no shareholder would want to invest in the firm. Therefore $\xi(\mathrm{s}, \mathrm{x})=0$ on a set of $(\mathrm{s}, \mathrm{x})$ of positive $\mathrm{f}_{1}$ - measure. On that set, however, (3.6) implies that $\theta(\mathrm{x}) \gamma(\mathrm{s})$ must depend on $\mathrm{s} / \mathrm{x}$ only, and non-trivially so in view of

3 The results in Holmstrom (1979) and Shavell (1979) suggest this result. Their logic is: If $\mathrm{x}$ is random, $\mathrm{s}$ is not a sufficient statistic for $\mathrm{y}$. Since $\mathrm{x}$ adds information about $y$, it should be used together with $s$ to allocate real consumption to the agent (and our renegotiation proof contract ignores $\mathrm{x}$ in setting real consumption). But if $\mathrm{x}$ is nonrandom, $\mathrm{s}$ is a sufficient statistic for $\mathrm{y}$. There is no further informative signal, and the Holmstrom-Shavell results no longer imply that the renegotiation proof contract is inefficient -- indeed the renegotiation proof contract is then second-best. 
the incentive compatibility condition. We now derive a contradiction to this last statement. Eq. (3.3) says that $\theta$ is proportional to $\mathrm{E}\left\{\mathrm{U}^{\prime}() \mid. \mathrm{x}\right\}$, and since the distribution of the ratio s/x is independent of $\mathrm{x}, \mathrm{E}\left\{\mathrm{U}^{\prime}() \mid. \mathrm{x}\right\}$ must be independent of $\mathrm{x}$. Therefore, $\theta(\mathrm{x})$ must be constant. But then $\theta(x) \gamma(s)$ is independent of $x$, which can only be true if $\theta(x) \gamma(s)$ does not depend on $\mathrm{s} / \mathrm{x}$-- a contradiction.

Lucas (1972, Theorem 5) proves that equilibrium under a predictable money supply rule is Pareto optimal the class of non-random allocations, i.e., allocations that depended on the real shock alone. Our Theorem 2 says more: Predictable money strictly dominates a random moneysupply rule.

\section{Positive Implications}

THEOREM 3 (MONEY HAS REAL EFFECTS): Changes in $\mathrm{x}$ alter the consumption of a subset of agents of positive measure.

PROOF: Suppose $\mathrm{x}$ was neutral. As in the proof of Theorem 2, the worker is risk-averse, and this warrants at least partial insurance. Therefore $\xi(s, x)=0$ on a set of $(s, x)$ of positive $f_{1}$ measure. Neutral money implies that $\delta(x) / x$ is a constant, and the equilibrium contract would be of the form $w(s, x)=x W(s / x)$ for some function $W($.$) . Then from (3.6), this would imply$ that $\theta(\mathrm{x}) \gamma(\mathrm{s})$ would be a function of the ratio $\mathrm{s} / \mathrm{x}$ only. And since $\theta(\mathrm{x})$ is constant, this means that $\gamma(\mathrm{s})[=\gamma(\mathrm{xy})]$ is a constant, except on a set of zero $\mathrm{f}_{1}$-measure. But then the incentive compatibility condition to problem (3.7) could not be met.

Subtracting $\delta(x) / x+\beta(K-1)$ from $c(s, x ; \gamma)$ in (3.6), real wages are,

$$
w(x y, x) / x=\min \left\{y, U^{\prime}-1[\theta(x) \gamma(x y)]-[\delta(x) / x+\beta(K-1)]\right\}
$$

Aggregate output is unity, and so labor's share is

$$
1-\delta^{*}(\mathrm{x})=\int[\mathrm{w}(\mathrm{xy}, \mathrm{x}) / \mathrm{x}] \mathrm{dF}_{1}(\mathrm{y})
$$

and $\delta^{*}(\mathrm{x}) \equiv \delta(\mathrm{x}) / \mathrm{x}$ is the share of asset holders. Substituting from (5.1) into (5.2) and subtracting $\delta^{*}(\mathrm{x})$ from both sides leaves us with the implicit function that relates $\delta^{*}, \theta$, and $\gamma$ 
as follows:

$$
1=\int \min \left\{y+\delta^{*}(x), \quad U^{\prime}-1[\theta(x) \gamma(x y)]-\beta(K-1)\right\} d^{2}(y)
$$

\section{THEOREM 4 (INFLATION LOWERS STOCK RETURNS): If}

(a) The likelihood ratio $f_{1}(y) / f_{0}(y)$ is increasing in $y$, with a slope that is bounded away from zero,

(b) $U(c)$ is quadratic as specified in Theorem 1,

(c) $\operatorname{Var}(\mathrm{x})$ is sufficiently small,

then the share of capital $\delta^{*}(\mathrm{x})$ is decreasing in $\mathrm{x}$, and the share of labor, $1-\delta^{*}(\mathrm{x})$, is increasing in $\mathrm{x}$.

PROOF: The proof proceeds in five steps:

(i) Suppose that for each fixed $y, \theta(x) \gamma(x y)$ is an increasing (decreasing) function of $x$. Since neither $y$ nor $\beta(K-1)$ depend on $x$, for (5.3) to continue to hold when $x$ changes, $\delta^{*}(\mathrm{x})$ must move in the opposite direction from $\mathrm{U}^{-1}[\theta(\mathrm{x}) \gamma(\mathrm{xy})]$. And since $\mathrm{U}^{-1}$ is a decreasing function, this proves $\delta^{*}(\mathrm{x})$ is increasing (decreasing) in $\mathrm{x}$ as $\theta(\mathrm{x}) \gamma(\mathrm{xy})$ is an increasing (decreasing) function of $x$.

(ii) If $U$ is quadratic, $\theta(x)$ is a constant. This is because $U^{\prime}$ is linear in c, so that in (3.3), $E\left\{U^{\prime}[c(s, x)] \mid x\right\}$ just depends on mean consumption, which equals $Y+\beta(K-1)$ for all $x$.

(iii) From (i) and (ii), if $\gamma(\mathrm{s})$ is monotone increasing (decreasing), so is $\delta^{*}(\mathrm{x})$.

(iv) Rearrange eq. (b.3) of the appendix to get:

$$
\gamma(s)=\frac{\lambda}{1+\mu\left[1-\tau_{0}(s) / \tau_{1}(s)\right]}
$$

where $\tau_{n}(s) \equiv \int h_{n}(s, x) d x$, for $n=0,1$. Neither $\lambda$ nor $\mu$ depend on $s$, and they both are strictly positive because the constraints they refer to in problem (3.8) are binding. Therefore, $\gamma(s)$ is decreasing in $s$ if the ratio $\tau_{1}(s) / \tau_{0}(s)$ is increasing, and vice-versa.

(v) As $\operatorname{Var}(\mathrm{x})$ gets small, $\mathrm{g}(\mathrm{x})$ converges to a unit mass on $\mathrm{x}=1$, and $\tau_{\mathrm{n}}(\mathrm{s})$ converges to $f_{n}(s)$. Condition (c) then guarantees that $\gamma(s)$ is a strictly increasing function.

The assertion now follows from claims (i) through (v). 


\section{Discussion of the key assumptions}

6.A. Asymmetry of risk attitudes. Even if preferences are arbitrary, a second-best risksharing contract generally differs from a renegotiation-proof contract, and so nonneutrality per se does not hinge on this asymmetry. But proposition 4 does require it. It arises naturally if there is a stock market. It could also arise from different tastes, as in Kihlstrom and Laffont (1979).

6.B. Agency problem: If there were no agency problem, risk-averse agents would be fully insured. But this is evidently not true; most contracts contain incentive clauses.

6.C. Neither party can see y: Output is hard to observe when the product is differentiated, or complex, or new. Quality is often defined by the price that the product sells for -- new goods are an example. And how does one measure the quality of a complex job such as that of a CEO or of the marketing or sales division without seeing the sales figures?

6.D. $\mathrm{x}$ is observed with delay. It takes time for the CPI (the empirical counterpart of $\mathrm{x}$ ) to be gathered reliably (Bullard, 1994) But in the U.S. economy at present, the variance of the CPI is small, and there are other signals about the price level that the firm can use:

(a) If the firm has other workers doing the same thing, $x$ can be precisely estimated if the workers are many, and if their y's are independent, which they probably rarely are.

(b) Aggregate signals about the price level such as interest rates and the money supply are imperfectly correlated with the price level. Even money-supply announcements are substantially revised -- see Mankiw et al (1984).

6.E. Parties can not avoid renegotiation: One way to avoid a renegotiation is to officially involve a third party who gets a payment in the event that the original contract is renegotiated, or to officially restrict the frequency of meetings. But it is known that such commitments can be circumvented at the interim stage through unofficial "side contracts".

6.F. No real shocks: In the model, $x$ denotes the supply of money, and the general price level. In the real world, the two do not coincide. If we put in real shocks, we would free up the relation between the two. The price level, $x$, would depend on both the money shock and the real shock, and agents would need to forecast both. But nothing else would really change. For example, there might be shocks to the velocity of money. 


\section{Other issues}

7.A. Other explanations for the negative relation between inflation on stock returns: First, if the money-supply is fixed and velocity is constant, a spurious relation can arise: A favorable shock to output will raise output supplied and lower the equilibrium price level, thereby causing a negative correlation between output and the price level. Fama (1981) and Kydland and Prescott (1990) make this point. But the evidence in Chen, Chan, Ross and others refers to a partial correlation between surprise inflation and stock returns; they include Industrial Production as a separate regressor separately in their regressions, and this variable should capture the aggregate shock effect. Second, perhaps liquidity lowers the probability of bankruptcy and allows weaker firms to survive. Third, the effect may be policy-induced: After a positive inflation surprise, the market may expect the Fed to tighten the money supply. If this would ordinarily lead interest rates to rise through a liquidity effect, the market may rationally anticipate this, and induce stock prices to fall. Finally, taxes are not indexed -- e.g., depreciation allowances are nominal. When inflation is high, their real value goes down, and so does the value of the firm. Maher and Nantell (1983) discuss nominal tax-effects in detail.

7.B. Micro evidence on indexation: Proposition 4 says that real wages should rise with a money shock, or that the elasticity of the nominal wage with respect to price surprises should exceed unity. Micro evidence on the whole does not favor this implication. In panel data, Card (1990) and McLaughlin (1994) find an elasticity of only 1/2. Keane (1993), however, finds that manufacturing real wages do rise with M1 shocks, and this (together with Christiano and Eichenbaum's evidence that money shocks raise the aggregate real wage) provides some support for our result.

7.C. Other interpretations: Our model could apply to other principal-agent situations. The principal may be a firm's headquarters, and the agent a subsidiary or franchise, and where headquarters has imperfect information about events in its franchise -- an informational asymmetry that Radner (1992) has recently stressed. Or the principal can be a group of shareholders and the agent could be the management. Under the first interpretation, our model suggests that small firms -- risk averse franchises -- should do better relative to large firms during monetary expansions. In line with this, Gertler and Gilchrist (1994) and Oliner and Rudebusch (1994) find that money distributions disproportionately stimulate small firms, and Chevalier and Scharfstein (1995) find markups to be more cyclical for small firms than for large firms.

7.D. Related literature: Closest to what we do is Azariadis (1978). He introduces risk-sharing 
between workers and firms into the Lucas (1972) model. He divides agents into two types: workers and entrepreneurs. The main difference is that he assumes (a) contractable effort (chosen after the price shock is realized) and (b) no stock market.

\section{Conclusions}

We have analyzed an equilibrium principal-agent model when there is nominal risk. The key feature of the problem is that the consumption deflator is random and observed sometime after the effort is exerted. This would not matter if effort were observable and contractable; in this case, first-best contracts would insure the agent, and they would be renegotiation-proof. But effort is not contractible, and in order to induce the agent to work, second-best contracts do not insure the agent fully. They do eliminate all nominal risk for the parties (by fully indexing the terms of the contracts to the price level) but they are not renegotiation-proof.

Foreseeing the renegotiation, the parties to the contract will write one that is renegotiation-proof. Under such a contract, nominal shocks affect real consumption. Since the argument should apply in many situations, it will have macroeconomic implications, one of which is short-run non-neutrality of money. We have found that surprise money is likely to redistribute consumption and welfare towards workers, and away from shareholders.

\section{References:}

Azariadis, Costas, “Escalator Clauses and the Allocation of Cyclical Risks," Journal of Economic Theory 18 (1978): 119 - 155.

Benabou, Roland, "Inflation and Markups,: Theories and Evidence From the Retail Sector," European Economic Review 36 (1992): 566 - 574.

Blanchard, Olivier, "Movements in the Equity Premium," Brookings Papers in Economic Activity 2 (1993): $75-118$.

Blanchard, Olivier and Pierre Muet, "Competitiveness through Disinflation: An Assessment of the French Macroeconomic Strategy," Economic Policy (April 1993): 12 - 56.

Bullard, James, "How Reliable are Inflation Reports?" Monetary Trends, Federal Reserve Bank of St. Louis (February 1994): 3 - 4.

Card, David, "Unexpected Inflation, Real Wages, and Employment Determination in Union Contracts," American Economic Review 80, no. 4 (September 1990): 669 - 88. 
Chan, K.C., Nai-Fu Chen, and David Hsieh, "An Exploratory Investigation of the Firm Size Effect, " Journal of Financial Economics 14 (1985): 451 - 471.

Chen, Nai-Fu, Richard Roll, and Stephen Ross, "Economic Forces and the Stock Market," Journal of Business 59, no. 3 (1986): 383 - 403.

Chevalier, Judith, and David Scharfstein, "Liquidity Constraints and the Cyclical Behavior of Markups," American Economic Review (Papers and Proceedings) (May 1995).

Christiano, Lawrence, and Martin Eichenbaum, "Liquidity Effects, Monetary Policy, and the Business Cycle," NBER working paper \# 4129, August 1992.

Eden, Benjamin, "The Adjustment of Prices to Monetary Shocks when Trade is Sequential and Uncertain," Journal of Political Economy 102, no. 3 (June 1994): 493 - 509.

Fama, Eugene, "Stock Returns, Real Activity, Inflation, and Money," American Economic Review 71, no. 4 (September 1981): 545 - 65.

Gertler, Mark, and Simon Gilchrist, "Monetary Policy, Business Cycles, and the Behavior of Small Manufacturing Firms," Quarterly Journal of Economics (May 1994):

Gordon, Robert, "Why U.S. Wage and Employment Behaviour Differs from that in Britain and Japan," Economic Journal 92 (March 1982): 13 - 44.

Grossman, Sanford, and Lawrence Weiss, "A Transactions-Based Model of the Monetary Transmissions Mechanism" American Economic Review 73 (1983): 871-880.

Holmstrom, Bengt, "Moral Hazard and Observability," The Bell Journal of Economics 10 (1979): 74 - 91.

Kaskarelis, Ioannis, "Inflation and the Markup in the UK Manufacturing Industry", Oxford Economics Bulletin of Economics and Statistics 55, no 4 (1993): 391-408.

Keane, Michael, "Nominal Contracting Theories of Unemployment: Evidence from Panel Data," American Economic Review 83, no. 4 (September 1993): 932 - 952.

Kihlstrom, Richard, and Jean-Jacques Laffont, "A General Equilibrium Entrepreneurial Theory of Firm Formation Based on Risk Aversion," Journal of Political Economy 87 (August 1979): $719-748$

Kydland, Finn, and Edward Prescott, "Business Cycles: Real Facts and a Monetary Myth," Federal Reserve Bank of Minneapolis Quarterly Review 14, no. 2 (Spring 1990): 3 - 18.

Lucas, Robert, "Expectations and the Neutrality of Money," Journal of Economic Theory 4 (1972): 103-124.

Luenberger, David, Optimization by Vector Space Methods New York: Wiley 1969.

Maher, Michael W. and Timothy Nantell, "The Tax Effect of Inflation: Depreciation, Debt, and Miller's Equilibrium Tax Rates." Journal of Accounting Research 21, no. 1 (1983): 329-340.

Mankiw, Gregg, David Runkle, and Matt Shapiro, "Are Preliminary Estimates of the Money 
Stock Rational Forecasts?" Journal of Monetary Economics (1984): 15-27.

Maskin, Eric S. and Jean Tirole, "The Principal-Agent Relationship with an Informed Principal: Common Values." Econometrica 60 (January 1992):1 - 42.

McLaughlin, Ken, "Rigid Wages?" Journal of Monetary Economics 34 (1994): 383-414.

Oliner, Stephen and Glenn Rudebusch, "Is There a Broad Credit Channel," mimeo, Federal Reserve Board, 1994.

Perloff, Jeffrey, and Steven Salop, "Equilibrium with Product Differentiation," Economic Studies (1985): 107 - 120.

Radner, Roy, "Hierarchy: The Economics of Managing," Journal of Economic Literature 30, no. 3 (1992): 1382-1415.

Rotemberg, Julio, "A Monetary Equilibrium with Transactions Costs," Journal of Political

Economy 92, no. 1 (January 1984): 40 - 58.

Shavell, Steven, "Risk Sharing and Incentives in the Principal and Agent Relationship," The Bell Journal of Economics 10 (1979): 55-73.

Stokey, Nancy, and Robert Lucas, Recursive Methods in Economic Dynamics, Cambridge:

Harvard University Press, 1989.

Sheshinski, Eytan, and Yoram Weiss, "Inflation and Costs of Price Adjustment," Review of

Economic Studies 44 (June 1977): 287 - 303.

\section{Appendix}

PROOF OF PROPOSITION 1: Let $\mathrm{R}$ denote the size of the investor's risky portfolio, and K$\mathrm{R}$ the size of his safe portfolio. Suppose he puts a fraction $(1-\varepsilon)$ of his risky investment in a diversified portfolio of all firms other than firm $j$, and the remainder in firm $j$. The number of shares of firm $j$ that he buys is $\varepsilon R / V_{j}$, and if each other firm's price is $V$, his holdings of each other firm will equal $(1-\varepsilon) R / V$. The dividend income from this portfolio is

$$
[(1-\varepsilon) R / V] \int \delta\left(s_{J}, x\right) d J+\left[\varepsilon R / V_{j}\right] \delta\left(s_{j}, x\right)=[(1-\varepsilon) R / V] \delta(x)+\left[\varepsilon R / V_{j}\right] \delta\left(s_{j}, x\right)
$$

The equality follows because by the law of large numbers,

$$
\int \delta\left(s_{\mathrm{J}}, \mathrm{x}\right) \mathrm{dJ}=\int \delta(\mathrm{s}, \mathrm{x})(1 / \mathrm{x}) \mathrm{f}_{1}(\mathrm{~s} / \mathrm{x}) \mathrm{dx} \equiv \delta(\mathrm{x})
$$


The cost of this portfolio is just $\mathrm{R}$. Investor i's expected utility then is

$$
\int U\left(x^{-1}\left\{(1-\varepsilon) R \delta(x) / V+\varepsilon R \delta\left(s_{j}, x\right) / V_{j}+x \beta(K-R)+w\left(s_{i}, x\right)\right\}\right) x^{-1} f_{l}\left(s_{j} / x\right) d s_{j} h_{1}\left(s_{i}, x\right) d s_{i} d x
$$

From now on, we drop the subscript i. The first order condition for a maximum with respect to $\varepsilon$ is:

$$
\left[R / V_{j}\right] \int x^{-1} U^{\prime}(.) \delta\left(s_{j}, x\right) x^{-1} f_{l}\left(s_{j} / x\right) d s_{j} h_{1}(s, x) d s d x-[R / V] \int U^{\prime}(.) \delta(x) h_{1}(s, x) d s d x=0
$$

(because $\int x^{-1} f_{1}\left(s_{j} / x\right) d s_{j}=1$ integrates out of the second term). Evaluating $U($.$) at \varepsilon=0$,

$$
V_{j} / V=\frac{\int\left\{\int U^{\prime}[c(s, x)] h_{1}(s, x) d s\right\}\left\{\int \delta\left(s_{j}, x\right) x^{-2} f_{1}\left(s_{j} / x\right) d s_{j}\right\} d x}{\iint U^{\prime}[c(s, x)] \delta(x) x^{-1} h_{1}(s, x) d s d x}
$$

In equilibrium, $\int \delta\left(s_{j}, x\right) x^{-1} f_{1}\left(s_{j} / x\right) d s_{j}=\delta(x)$, so that $V_{j} / V=1$. Finally, the condition of optimality for $\mathrm{R}$ implies

$$
\int U^{\prime}[c(s, x)]\{\delta(x) / x V-\beta\} h_{1}(s, x) d s d x=0
$$

and the claim follows.

PROOF OF THEOREM 1: By Lemma 3, when the utility function is quadratic, $\theta(x)$ is a constant. Problem (3.7) now no longer depends on $\theta(x)$, as the latter is proportional to $1 / x$. The proof has 5 steps. The first four steps deal with problem (3.7). They show that a solution for $\gamma$ (a) exists, (b) is unique, (c) is in a Lipschitz family with a constant that does not depend on $\delta$, and (d) is continuous in $\delta$. Step (e) shows that the reverse map, from $\gamma$ to $\delta$ is continuous, shows that the composite mapping $\gamma \rightarrow \delta \rightarrow \gamma$ is continuous, and applies a fixed point theorem. We now describe each step in detail.

(a) Existence of optimal $\gamma$. Then $\gamma(\mathrm{s})$ is the marginal utility of consumption. Since $\mathrm{x}$ and $\mathrm{y}$ are bounded, so is $\mathrm{s}$. Therefore the control $\gamma(\mathrm{s})$ maps a bounded interval in $\mathrm{R}$ into $\mathrm{R}$. 
The $\gamma$ are bounded uniformly. From below, it is bounded away from zero by the inequality in (iii), which in view of the limited liability condition makes it impossible for consumption to ever reach its bliss level of ab (the level of consumption at which marginal utility is zero). Functions $\gamma$ that fall below this value can be replaced by other functions that give the parties the same payoffs. By a symmetric argument, we can bound $\gamma(\mathrm{s})$ from above as follows: Since $\mathrm{K}>1$, consumption is bounded from below by the payoff from private storage. The definition of $\mathrm{c}(\mathrm{s}$, $\mathrm{x} ; \boldsymbol{\gamma}$ ) does not allow the firm to affect the worker's consumption through negative wages even if it should choose a function $\gamma$ that would imply a negative wage. Therefore neither the criterion nor the constraints are affected by any $\gamma$ that violated this constraint. Therefore we know that if a maximal $\gamma$ exists, its range will lie in a compact subset of the line. Next, we shall constrain $\gamma$ to a family of Lipschitz functions, and show [in (c) below] that this constraint does not bind at the optimum. With the sup norm $\|$.$\| on functions \gamma$, the space of controls is then compact. The two constraints confine the controls to closed subsets of this compact set, and therefore the set of admissible controls is compact. The criterion is clearly continuous in $\gamma$. Therefore, by Weierstrass's theorem, a maximal $\gamma$ exists.

(b) Uniqueness of optimal $\gamma$. Because of the incentive compatibility constraint, we need a theorem that does not require convexity of the control set -- Theorem 2 of Luenberger (1959, p. 221). Every assumption in that theorem is met here. We have two real-valued constraints, so the dual space is $\mathrm{R}^{2}$. The Lagrangean (3.8) is Frechet differentiable in $\gamma$, and $\gamma$ affects it only through $c(s, x ; \gamma)$, which on the unconstrained region equals $U^{\prime-1}(\gamma(s))=b[a-\gamma(s)]$. Applying the chain rule, the first-order condition is that for all $s$,

$$
-\left\{\tau_{1}(s)+\mu\left[\tau_{1}(s)-\tau_{0}(s)\right]\right\} \gamma(s)+\lambda \tau_{1}(s)=0
$$

where $\tau_{n}(s) \equiv \int h_{n}(s, x) d x$. The second order condition is

$$
\tau_{1}(s)+\mu\left[\tau_{1}(s)-\tau_{0}(s)\right]>0
$$

Because the integral is a sum, (b.2) ensures the global concavity of the Lagrangean in $\gamma$ at the point $(\lambda, \mu)$. From (b.1)

$$
\gamma(s)=\lambda \tau_{1}(s) /\left\{\tau_{1}(s)+\mu\left[\tau_{1}(s)-\tau_{0}(s)\right]\right\}
$$

The numerator of (b.3) is positive. The denominator coincides with the left hand side of (b.2). 
Since $\gamma(\mathrm{s})$ must be strictly positive, (b.2) is met. Thus we have shown that a unique maximum to the Lagrangean exists for the control $\gamma(\mathrm{s})$ for $(\lambda, \mu)$ fixed.

To show that this is also a unique maximum for the problem (3.7), one still has to show that $(\lambda, \mu)$ are unique. First, if $\lambda$ is given, then $\mu$ will be uniquely defined. The reason is as follows: both constraints must bind at the optimum. If there was more then one value of $\mu$, (b.3) shows that the incentive compatibility condition would not bind at one of these (divide numerator and denominator by $\tau_{1}(s)$, and observe that $d \gamma / d s$ is increasing in $\mu$ ). So the incentive compatibility condition could not bind at more than a single $\mu$ for a given $\lambda$. So conditional on $\lambda, \mu$ is unique, and it is enough to show that $\lambda$ is unique. From Luenberger (1969, p. 222, Theorem 1) $\lambda$ is the derivative of the maximized criterion with respect to $\beta$ if this derivative exists. Since $\theta(x)=1$, since on the unconstrained region $-w(s, x)=\beta(K-1)$ $+\delta(x) / x-c(s, x ; \gamma)$, and since on that region $c(s, x ; \gamma)=b[a-\gamma(s)]$, the constraint reads

$$
\int\{\mathrm{s}+\beta(\mathrm{K}-1)+\delta(\mathrm{x}) / \mathrm{x}-\mathrm{b}[\mathrm{a}-\gamma(\mathrm{s})]\} \mathrm{h}_{1}(\mathrm{~s}, \mathrm{x}) \mathrm{dsd} \mathrm{x} \geq \beta,
$$

where the domain of integration is $(s, x)$ for which $c(s, x)=U^{\prime-1}(\gamma(s))$. Let $\gamma_{\beta}$ be the optimal policy at $\beta$, and $v(\beta, \gamma)$ the criterion evaluated at the policy $\gamma$. Let $v(\beta)$ denote the maximized criterion, i.e., $\mathrm{v}(\beta)=\mathrm{v}\left(\beta, \gamma_{\beta}\right)$. When $\beta$ shifts up by an amount $\Delta$, the shareholders constraint will be met if a new policy $\gamma_{\Delta}$ is put in place under which $\int b\left[\gamma_{\Delta}(s)-\right.$ $\gamma(\mathrm{s})]\} \mathrm{h}_{1}(\mathrm{~s}, \mathrm{x}) \mathrm{dsdx}=\Delta$. To attain such a transfer to the shareholders, a feasible policy that does not disturb the incentive compatibility constraint is one that transfers a constant marginal utility of income. Since the marginal utility of income in state $s$ is $\gamma(\mathrm{s})$, the worker must give up $\mathrm{D} / \gamma(\mathrm{s})$ units of consumption in state $\mathrm{s}$ to give up $\mathrm{D}$ utils in that state. We are about to define these policies in terms of first order derivatives, so that for fixed $\Delta>0$, there will be an error that (because U(.) is analytic) is of order $O\left(\Delta^{2}\right)$. So consider the policies $\gamma_{\Delta}(\mathrm{s})^{+}=\gamma_{\beta}(\mathrm{s})+$ $\mathrm{D}^{+}(\Delta) / \gamma_{\beta}(\mathrm{s})$, and $\gamma_{\Delta}(\mathrm{s})^{-}=\gamma_{\beta+\Delta}(\mathrm{s})-\mathrm{D}^{-}(\Delta) / \gamma_{\beta+\Delta}(\mathrm{s})$ where $\mathrm{D}^{+}(\Delta)=\Delta / \int\left[\mathrm{b} / \gamma_{\beta}(\mathrm{s})\right] \mathrm{h}_{1}(\mathrm{~s}, \mathrm{x}) \mathrm{dsdx}$. and $\mathrm{D}^{-}(\Delta)=\Delta / \int\left[\mathrm{b} / \gamma_{\beta+\Delta}(\mathrm{s})\right] \mathrm{h}_{1}(\mathrm{~s}, \mathrm{x}) \mathrm{dsdx}$. The policy $\gamma_{\Delta}(\mathrm{s})^{+}$is feasible at $\beta+\Delta$, which means that (ignoring terms of order $\Delta^{2}$ ),

$$
\mathrm{v}(\beta+\Delta) \geq \mathrm{v}\left(\beta, \gamma_{\Delta}^{+}\right)=\mathrm{v}(\beta)-\mathrm{D}^{+}(\Delta)
$$

and and the policy $\gamma_{\Delta}(s)^{-}$is feasible at $\beta$. This means that

$$
\mathrm{v}(\beta) \geq \mathrm{v}\left(\beta, \gamma_{\Delta}^{+}\right)=\mathrm{v}(\beta)+\mathrm{D}^{-}(\Delta)
$$


Therefore

$$
\frac{-\mathrm{D}^{+}(\Delta)}{\Delta} \leq \frac{\mathrm{v}(\beta+\Delta)-\mathrm{v}(\beta)}{\Delta} \leq \frac{-\mathrm{D}(\Delta)}{\Delta}
$$

We substitute from the definition of $D($.$) to conclude that the right-hand side and the left-hand$ side of the above pair of inequalities must converge to the same well-defined limit as long as $\int\left[1 / \gamma_{\beta}(s)\right] h_{1}(s, x) d s d x$ is continuous in $\beta$. And using the functional form in (b.3), this could fail only if the criterion itself was discontinuous in $\beta$. But this would contradict Berge's Theorem of the maximum.

(c) A uniform Lipschitz constant. (b.3) implies $\gamma(\mathrm{s})=\lambda /\left\{1+\mu\left[1-\tau_{0}(\mathrm{~s}) / \tau_{1}(\mathrm{~s})\right]\right\}$.

Since $\gamma(s)$ is bounded uniformly in $[s, \delta()$.$] and since \lambda$ and $\mu$ do not depend on $s$, it follows that $\lambda$ and $\lambda / \mu$ are finite. Then it is sufficient that $\tau_{1}(\mathrm{~s}) / \tau_{0}(\mathrm{~s})$ be Lipschitz. Now $\tau_{\mathrm{n}}(\mathrm{s})=$ $\int(1 / x) f_{n}(s / x) g(x)$. Since by (i) $x$ is bounded away from zero, and by (ii) $f_{1}$ and $f_{0}$ are Lipschitz. So $\gamma(\mathrm{s})$ is Lipschitz with a constant not depending on $\delta($.$) .$

(d) Continuity of $\gamma$ in $\delta$ and $\theta$ : We use the sup norm $\|$.$\| on \delta$ as well. Since $\gamma$ is in a Lipschitz family, $\gamma_{1}(s) \rightarrow \gamma_{2}(s)$ pointwise in $s$ is equivalent to $\left\|\gamma_{1}-\gamma_{2}\right\| \rightarrow 0$. So we only need to show that $\gamma(\mathrm{s})$ is continuous in $\delta$ at each s. From (b.3), this follows if $\lambda$ and $\mu$ are continuous. Now the criterion and the constraints are continuous in $\delta$, and so by Berge's theorem of the maximum, the set of maximizing values for $\gamma(\mathrm{s})$ is u.h.c. in $\delta$, since by (b) above it is unique, it must be continuous.

(e) Existence of equilibrium $\psi$ : We shall use Schauder's fixed point theorem, as stated in Theorem 17.4 of Stokey and Lucas (1989). Lipschitz families are equicontinuous. The set of bounded functions $\gamma$ discussed in (a) is convex. With the sup norm, $\delta$ [defined in terms of $\gamma$ by (3.6) (3.2) and (3.1)] is continuous in $\gamma$. That is, given $\gamma$, equation (3.6) yields c, which is then used in (3.2) and (3.1) in that order, to get values for $w$ and then $\delta$. Given this value for $\delta$ the problem (3.8) then yields a new solution for $\gamma$. This defines a continuous map from $\gamma$ space into itself that goes as follows: $\gamma \rightarrow \mathrm{w} \rightarrow \delta \rightarrow \gamma$. Schauder's theorem then gives us a fixed point. 